\title{
Clinical and Microbiological Assessment of Carisolv and Polymer Bur for Selective Caries Removal in Primary Molars
}

\author{
Mohamed A Asal ${ }^{1}$, Abeer M Abdellatif ${ }^{2}$, Hossam E Hammouda ${ }^{3}$
}

\begin{abstract}
Aim and objective: To assess the efficacy of the new Carisolv system and Polymer bur (SmartbursII ${ }^{\oplus}$ ) for selective caries removal in primary molars clinically and microbiologically, compared with the conventional mechanical method.

Materials and methods: Sixty children with class I active carious lesions were selected. The children were randomly allocated to three groups $(n=20)$ according to the caries removal method. Under rubber dam isolation, dentin samples were taken before and after caries removal for microbial culture. Time spent in each technique was recorded. The clinical efficacy of caries removal was verified using caries detector dye. Patient satisfaction toward the treatment was evaluated using a facial image scale.

Results: The median of caries detector dye scores was significantly lower in the conventional group compared to others ( $p$ value $<0.05)$. The mean time for caries removal was the longest with Carisolv ( $p$ value $<0.05)$. The median of facial image scale scores was significantly higher in the conventional group compared with others ( $p$ value $<0.05$ ). The mean total viable bacterial count after caries removal was significantly higher in polymer bur group compared with others ( $p$ value $<0.05$ ). While, there was no significant difference between Carisolv and conventional groups ( $p$ value $>0.05$ ).

Conclusion: The clinical efficacy of caries removal was highest with the mechanical method. Carisolv took the longest time for caries removal. Patient satisfaction was higher with Carisolv and polymer bur than the mechanical method. The antimicrobial efficacy of Carisolv and the mechanical method was higher than the polymer bur.

Clinical significance: Carisolv is a viable alternative to the mechanical method in the management of dental caries, especially in children. Further studies are needed to assess the efficacy of caries removal by Smartburs $\|^{\circledast}$.

Keywords: Carisolv, Chemomechanical caries removal, Minimally invasive dentistry, Polymer burs, Selective caries removal.

International Journal of Clinical Pediatric Dentistry (2021): 10.5005/jp-journals-10005-1956
\end{abstract}

\section{INTRODUCTION}

Dental caries represents a major problem in pediatric dentistry. It is a multifactorial disease, resulting from the interplay between environmental, behavioral, and host factors. It results in demineralization of inorganic part and destruction of organic part of the tooth structure.

Usually, dentinal caries consists of two distinct successive layers, which are different in their clinical features as well as their chemical and microscopic structures. The outer layer (infected dentin) shows the distortion of the microstructure of dentinal tubules, irreversible degradation of collagen fibers, and significant bacterial penetration. Despite the possible discoloration, the inner layer (affected dentin) shows demineralization of the inter-tubular dentin, crystal deposition in the tubules, minimal collagen matrix degradation, and no bacterial invasion. Moreover, the inner layer is more resistant to proteolytic attack and caries progression. Therefore, the infected dentin should be removed and the affected dentin should be preserved, but the ability to discriminate between them and only remove the infected dentin remains a challenge. ${ }^{2}$

The conventional treatment of dental caries using rotary instruments is problematic in pediatric dentistry. It has many disadvantages as the perception of unpleasantness by patients, use of local anesthesia, and removal of both infected and affected dentin leading to unnecessary weakening of the tooth structure. Furthermore, it has deleterious thermal effects on pulpal tissue and there is a possibility of iatrogenic pulp exposure. ${ }^{3}$

Advances in cariology and dental materials have brought new approaches to the field of dentistry in terms of caries treatment
${ }^{1-3}$ Department of Pediatric Dentistry and Dental Public Health, Faculty of Dentistry, Mansoura University, Mansoura, Dakahlia, Egypt

Corresponding Author: Mohamed A Asal, Department of Pediatric Dentistry and Dental Public Health, Faculty of Dentistry, Mansoura University, Mansoura, Dakahlia, Egypt, Phone: +20 1276687730, e-mail: mohamed_asal@mans.edu.eg

How to cite this article: Asal MA, Abdellatif AM, Hammouda HE. Clinical and Microbiological Assessment of Carisolv and Polymer Bur for Selective Caries Removal in Primary Molars. Int J Clin Pediatr Dent 2021;14(3):357-363.

Source of support: Nil

Conflict of interest: None

modalities in the last few decades. The current practice is to keep the size of cavities as small as possible using minimal cavity preparation designs with adhesive restorations. Thus, the goal is to preserve the tooth structure as much as possible. ${ }^{4}$

Chemomechanical caries removal (CMCR) is a minimally invasive technique that removes the infected dentin by a chemical agent. This method not only removes the infected tissues but also preserves the healthy dental structure, avoiding pulp irritation and patient discomfort. Instead of drilling, this technique of caries removal is based on dissolution. This technique uses chemical agents aided by atraumatic mechanical force to excavate soft carious dentin. ${ }^{5}$

Another minimally invasive method of caries removal is by using polymer burs. Polymer bur is a unique rotary instrument 
made of a specially designed polymer material, which according to the manufacturer, selectively removes infected dentin without cutting the healthy dentin. It has specifically designed hardness which is higher than that of infected dentin, but less than that of affected dentin. Thus, allowing the bur to selectively remove the soft carious dentin while preserving the harder healthy dentin. ${ }^{6}$

Therefore, this study was conducted to assess and compare the efficacy of Polymer bur and Carisolv (as a representative of CMCR agents) in comparison to the conventional mechanical method clinically (efficacy, time, and patient satisfaction) and microbiologically.

The null hypothesis was that there would be no difference in the efficacy of caries removal of Polymer bur, Carisolv, or the conventional mechanical method clinically and microbiologically.

\section{Materials and Methods}

\section{Ethical Approval}

Protocol approval by the Institutional Ethical Committee of Mansoura University was considered before project processing (code no. 13020118).

\section{Study Design}

This was a randomized single-blinded clinical trial in 60 healthy cooperative children recruited from the pediatric dental clinic, Faculty of Dentistry, Mansoura University. Each participant was evaluated for one tooth only.

\section{Inclusion Criteria}

- Healthy, co-operative patients, aged between 4 years and 8 years with Class I (occlusal) active caries involving upper half of dentin in primary molars and confirmed using intraoral periapical radiographs.

- Absence of painful symptoms of irreversible pulpitis or pulp necrosis.

\section{Exclusion Criteria}

- Uncooperative children.

- Medically compromised children.

- Children with special care needs.

- Teeth with proximal caries.

- Developmental defects of teeth.

- Previously restored teeth.

\section{Informed Consent}

Agreement for participation in the study was gained from the parents in a written consent form and child assent was taken.

\section{Randomization and Allocation Concealment}

Participants who met the inclusion criteria were randomly allocated to three groups ( $n=20 /$ group, $n=60$ in total) according to the method of caries removal using the envelope randomization method. Once consent was obtained from the parent, the child was allowed to randomly select a sealed opaque envelope that contains one of the caries removal methods of the study.

\section{Study Groups}

- Group I (Polymer bur group): Teeth treated by Smartburs $\|^{\circledast}$ (SS White Burs, Inc., Lakewood, NJ, USA) for caries removal $(n=20)$.
- Group II (Carisolv group):

Teeth treated by New Carisolv ${ }^{\circledR}$ system (Mediteam, Sweden) for caries removal $(n=20)$.

- Group III (Conventional group):

Teeth treated by low-speed carbon steel round burs (Dentsply Maillefer, Switzerland) and excavators (Dentsply Maillefer, Switzerland) for caries removal $(n=20)$.

\section{Procedures}

The children were treated with the following sequence:

- The preoperative radiograph was taken to confirm that caries was involving the upper half of the dentin.

- Patient preparation and management: communication with the children was established by good rapport and non-verbal support.

- For patients allocated in groups (I and II): no local anesthesia was required, just topical anesthetic gel (benzocaine $20 \%$ ) was applied to allow application of the rubber dam without pain.

- For patients allocated in group III: benzocaine 20\% topical anesthesia gel was applied to the dried mucosa for 2 minutes and then local anesthesia was administrated.

- All teeth were isolated using a rubber dam.

- The outline form of the cavity was established using a highspeed drill to increase accessibility and visibility and also to remove the unsupported enamel margins.

- An initial baseline sample of the carious dentin was taken superficially from the lesion using a sterile spoon excavator.

- The dentin sample was immediately transferred into a sterile vial containing distilled water for microbial culture.

- Then, caries was removed according to the type of the group:

\section{Group I (Polymer Bur Group)}

- SS White Smartburs $\|^{\oplus}$ were used with a low-speed handpiece at 5,000-10,000 RPM to remove decayed dentin of size RA4, RA6, and RA8 according to the size of the carious lesion.

- Caries was excavated with circular, light brush stroke starting from the center and top of the carious lesion to the periphery as recommended by the manufacturer.

- The excavation was stopped when the instrument was macroscopically abraded and blunted and no longer able to remove tissue.

- Caries removal was verified with an explorer. If needed, a fresh Smartburs ${ }^{\circledR}$ was used to remove any remaining decay (Fig. 1).

\section{Group II (Carisolv Group)}

- The cap of the syringe was removed, then the static mixer, tip, and plunger were fit.

- The mixture was applied directly to the cavity and the carious dentin was thoroughly soaked with the gel for 30 seconds according to the manufacturer's recommendations.

- The softened dentin was removed using hand excavators.

- The gel was then rinsed with water. These procedures were repeated till no soft dentin was detected using the tactile method (Fig. 2). 

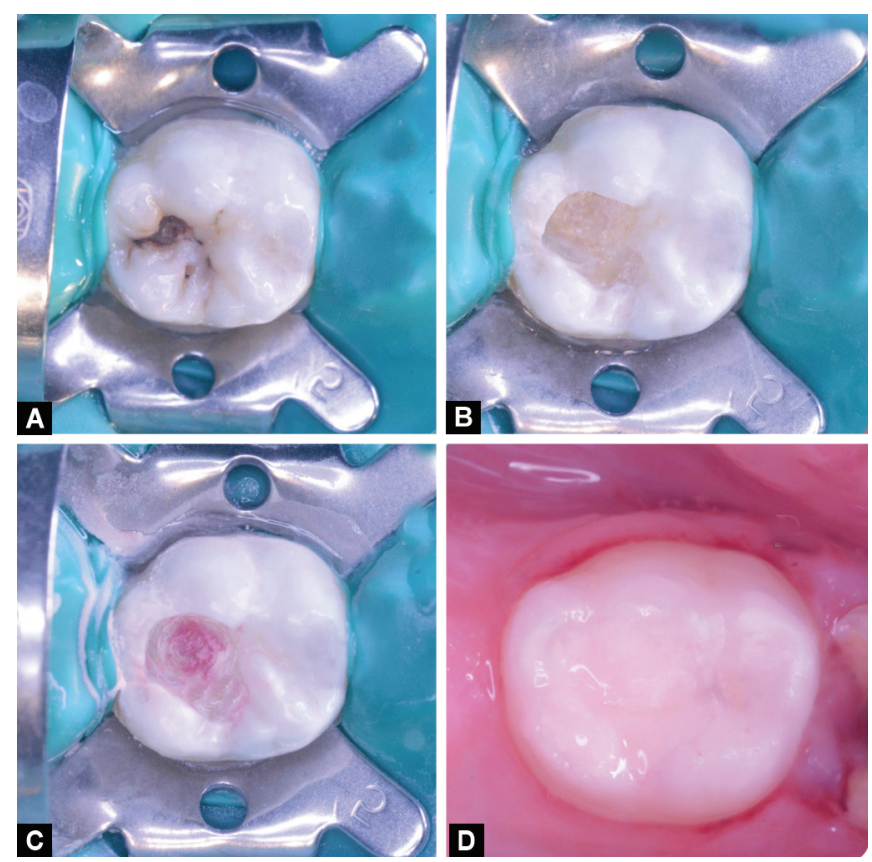

Figs 1 A to D: A clinical case of the tooth (85) treated by the polymer bur (Smartburs $\|^{\oplus}$ )
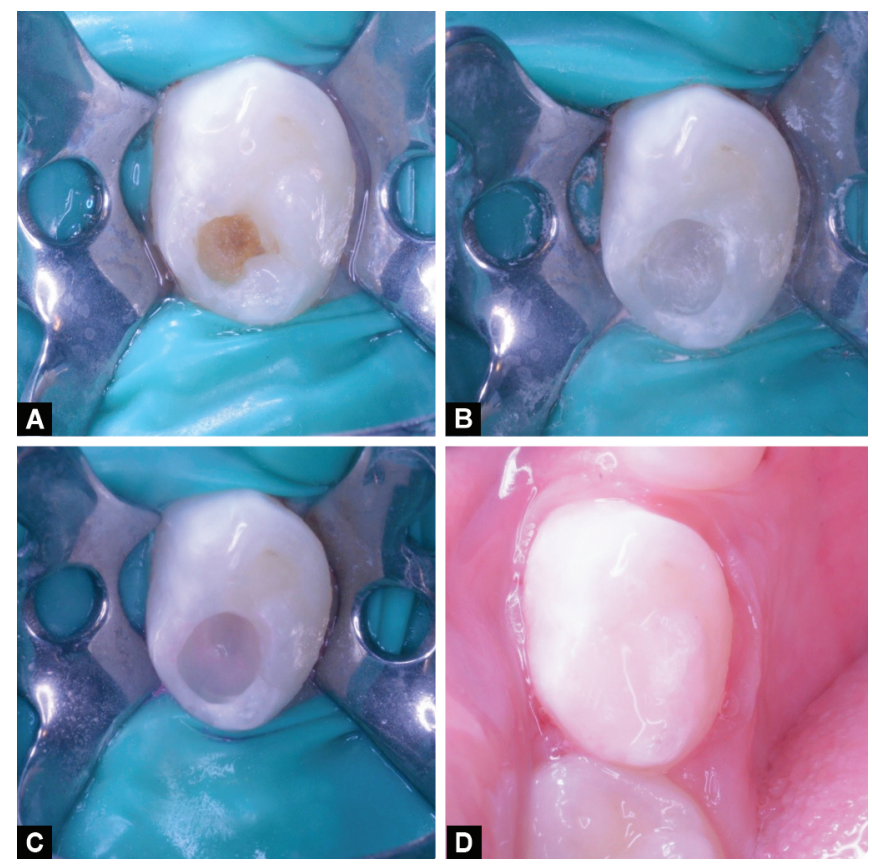

Figs 3 A to D: A clinical case of the tooth (85) treated by the conventional method

\section{Group III (Conventional Group)}

The carious dentin was removed using excavators and carbon steel round burs of ISO sizes 012, 014, and 016 at low-speed handpiece with water coolant depending on the size of the carious lesion. Caries removal terminated when the soft dentin was no more felt by the explorer (Fig. 3).

A sample of dentin was taken from the deepest part of the cavity floor in all groups using a sterile spoon excavator and transferred to a sterile vial containing distilled water. An adequate
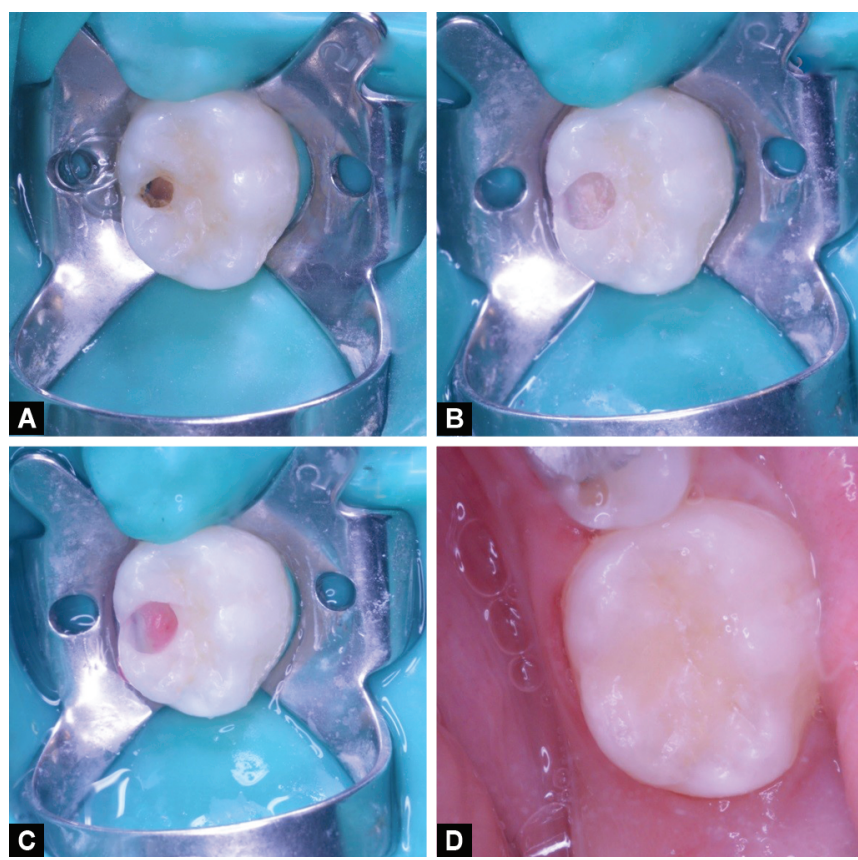

Figs 2A to D: A clinical case of the tooth (85) treated by the new Carisolv ${ }^{\oplus}$ system

amount of dentin particles was obtained for microbial culture and evaluation.

Remnants of caries were verified by using caries detector dye (Seek ${ }^{\circledast}$, Ultradent, Inc., USA) for 10 seconds followed by rinsing with water for 10 seconds.

All teeth were restored by resin-modified glass ionomer (GC Fuji II LC ${ }^{\circledR}$ GC Corp., Tokyo, Japan) and follow-up was done for 1 week for evaluation of any patient's complaint.

\section{Evaluation}

\section{Clinical Evaluation}

\section{Efficacy}

Remnants of caries were verified by using caries detector dye (Seek ${ }^{\circledR}$, Ultradent, Inc., USA) for 10 seconds followed by rinsing with water for 10 seconds. Efficacy is graded as complete or incomplete and numerically scored as $0,1,2,3,4,5$ using the criteria proposed by Munshi et al. ${ }^{7}$ (Table 1).

\section{Time}

Time spent in each technique was recorded in seconds starting from the time of caries removal using a stopwatch.

\section{Patient Satisfaction}

It was evaluated using the Facial Image Scale. The children were asked to point at which face they felt most like after each technique. The scale was scored by giving a value of 1 to the most happy face and 5 to the most unhappy face (Fig. 4).

\section{Microbiological Evaluation}

The collected dentin samples in sterile Eppendorf tubes containing $1 \mathrm{~mL}$ sterile distilled water were immediately transferred to the laboratory for microbial culture and evaluation. The collected samples were diluted using liquid Luria-Bertani (LB) media and then plated on LB agar plates. The LB agar plates were incubated 
Table 1: Scoring criteria for assessment of the efficacy of caries removal

\begin{tabular}{|c|c|}
\hline Score & Definition \\
\hline 0 & Caries completely removed. \\
\hline 1 & Caries present in the base of the cavity preparation. \\
\hline 2 & $\begin{array}{l}\text { Caries present in the base and/or in one wall of the cavity } \\
\text { preparation. }\end{array}$ \\
\hline 3 & $\begin{array}{l}\text { Caries present in the base and/or two walls of the cavity } \\
\text { preparation. }\end{array}$ \\
\hline 4 & $\begin{array}{l}\text { Caries present in the base and/or more than two walls of } \\
\text { the cavity preparation. }\end{array}$ \\
\hline 5 & $\begin{array}{l}\text { Caries present in the base, walls, and margins of the cav- } \\
\text { ity preparation. }\end{array}$ \\
\hline
\end{tabular}
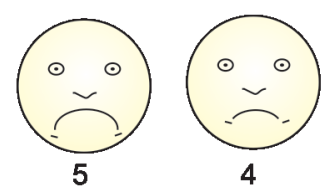

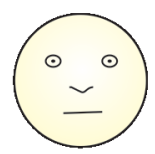

3

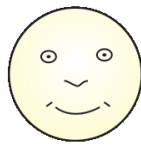

2

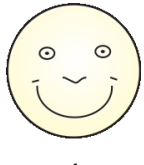

1
Fig. 4: Facial image scale with image scores

aerobically for 2 days at $37^{\circ} \mathrm{C}$. Then, the number of colonies was determined and expressed as colony forming units (CFU) per sample as follow:

$$
\mathrm{CFU}=\text { Number of colonies } \times(1 / \text { dilution })
$$

\section{Statistical Analysis}

Data were analyzed using the Statistical Package of Social Science (SPSS) program for Windows (Standard version 21). The normality of data was first tested with a one-sample Kolmogorov-Smirnov test.

Continuous variables were presented as mean \pm standard deviation (SD) for parametric data and median (min-max) for non-parametric data. ANOVA test was used to compare $>2$ means while Kruskal-Wallis test was used to compare $>2$ medians. In between group's comparison were tested by post hoc LSD test and Mann-Whitney test. data.

Spearman correlation was used to correlate continuous ordinal

\section{Level of Significance}

For all above mentioned statistical tests done, the threshold of significance is fixed at a $5 \%$ level ( $p$ value). The results were considered

- Non-significant when the probability of error is $>5 \%(p>0.05)$.

- Significant when the probability of error is $<5 \%(p \leq 0.05)$.

The smaller the $p$ value obtained, the more significant are the results.

\section{Results}

This study was carried out on 60 children aged between 4 years and 8 years selected from the Pediatric Dental Clinic, Faculty of Dentistry. The sample distribution according to age and gender are shown in Table 2. The patients were randomly divided into three groups (20 patients in each group): group I: Polymer bur group, group II: Carisolv group, and group III: conventional group.

\section{Results of Clinical Evaluation}

\section{Results of Efficacy (Caries Detector Dye Scores)}

Table 3 shows a comparison between the median values of the three groups regarding caries detector dye scores. The median of caries detector dye scores was significantly lower in the conventional group compared to the other two groups ( $p$ value $<0.05$ ).

There was no significant difference between the Polymer bur group and the Carisolv group ( $p$ value $>0.05$ ).

\section{Results of Time}

The mean time for caries removal was significantly longer in the Carisolv group (mean \pm SD) $(455.45 \pm 73.6)$ compared with $(129.20$ $\pm 44.17)$ in polymer bur and (113.25 \pm 37.6$)$ in the conventional group ( $p$ value $<0.05$ ).

On the other hand, no significant difference was observed among Polymer Bur and Conventional groups ( $p$ value $>0.05$ ).

\section{Results of Patient Satisfaction (Facial Image Scale)}

Table 4 shows a comparison between the median values of the three groups regarding facial image scale scores. The median of facial image scale scores was significantly higher in the conventional group compared to the other two groups ( $p$ value $<0.05$ ).

On the other hand, no significant difference was observed among polymer bur and Carisolv groups ( $p$ value $>0.05$ ).

\section{Results of Microbiological Assessment}

Table 5 shows a comparison between the mean values of the total viable bacterial count before caries removal by the three methods. It also shows a comparison between the total viable bacterial count after caries excavation by the three methods.

It showed that there is no significant difference between the three groups regarding the mean values of the total viable bacterial count before caries excavation ( $p$ value $>0.05$ ).

Regarding the mean values of total viable bacterial count after caries removal, there is a statistically significant difference between the groups ( $p$ value $<0.05$ ). The mean values of total viable bacterial count after caries removal was significantly higher in polymer bur group compared with the other two groups ( $p$ value $<0.05$ ).

On the other hand, no significant difference was observed between Carisolv and conventional groups ( $p$ value $>0.05$ ).

\section{Discussion}

Conventional caries removal methods involve using a high-speed hand-piece, low-speed hand-piece, and excavators to remove the carious dentin. This method undoubtedly improved the efficacy and efficiency of cavity preparation but has many inevitable disadvantages, such as perception of unpleasantness by patients, use of local anesthesia, removal of both infected and affected dentin which causes unnecessary weakening of the tooth structure, and also deleterious thermal effects on pulpal tissue and possibility of iatrogenic pulp exposure. ${ }^{3}$

Advances evolved in the field of dentistry that made conservation of tooth structure to the maximum. Chemomechanical caries removal and polymer burs are two minimally invasive techniques, which selectively remove the infected dentin while preserving affected dentin and sound tooth structure. They also help to eliminate the pain associated with the removal of carious dentin, thus introducing dental treatment to children in a painless manner. ${ }^{8,9}$ This in vivo study evaluated and compared the efficacy 
Table 2: Sample distribution according to age and gender of the children

\begin{tabular}{llllll}
\hline & & Polymer bur group $(n=20)$ & Carisolv group $(n=20)$ & Conventional group $(n=20)$ & $p$ value \\
\hline Age $($ mean \pm SD) & & $5.65 \pm 1.42(\%)$ & $6.60 \pm 1.50(\%)$ & $5.65 \pm 1.57(\%)$ & 0.77 \\
Gender & Male & $8(40)$ & $10(50)$ & $9(45)$ & 0.8 \\
& Female & $12(60)$ & $10(50)$ & $11(55)$ & \\
\hline
\end{tabular}

Data expressed as mean \pm SD and frequency (No-\%)

$\mathrm{SD}$, standard deviation; $\mathrm{p}$, probability

Test used: One-way ANOVA for data expressed as mean \pm SD and Chi-square for data expressed as frequency

Table 3: Caries detector dye scores among the studied groups

\begin{tabular}{lllll}
\hline $\begin{array}{l}\text { Caries detector } \\
\text { dye scores }\end{array}$ & $\begin{array}{l}\text { Polymerbur } \\
\text { group }\end{array}$ & $\begin{array}{l}\text { Carisolv } \\
\text { group }\end{array}$ & $\begin{array}{l}\text { Conventional } \\
\text { group }\end{array}$ & pvalue \\
\hline $\begin{array}{l}\text { Median (Min- } \\
\text { Max) }\end{array}$ & $1(1-2)$ & $1(0-3)$ & $0.5(0-1)$ & $<0.001^{*}$ \\
MW test & $\mathrm{P} 1=0.737, \mathrm{P} 2=<0.001^{*}, \mathrm{P} 3=0.001^{*}$ & \\
\hline
\end{tabular}

\section{MW: Mann-Whitney test}

P1: Comparison between polymer bur group and Carisolv group (nonsignificant difference)

P2: Comparison between polymer bur group and conventional group (significant difference)

P3: Comparison between Carisolv group and conventional group (significant difference)

Data expressed as median (minimum-maximum); $p$, probability; ${ }^{*}$, significance $<0.05$
Table 4: Facial image scale scores among the studied groups

\begin{tabular}{lllll}
\hline $\begin{array}{l}\text { Facial image } \\
\text { scale }\end{array}$ & $\begin{array}{l}\text { Polymerbur } \\
\text { group }\end{array}$ & $\begin{array}{l}\text { Carisolv } \\
\text { group }\end{array}$ & $\begin{array}{l}\text { Conventional } \\
\text { group }\end{array}$ & pvalue \\
\hline $\begin{array}{l}\text { Median } \\
\text { (Min-Max) }\end{array}$ & $1(1-3)$ & $1(1-3)$ & $2(1-5)$ & $0.015^{*}$ \\
MW test & P1 $=0.691, \mathrm{P} 2=0.028^{*}, \mathrm{P} 3=0.01^{*}$ & \\
\hline
\end{tabular}

MW: Mann-Whitney test

P1: Comparison between polymer bur group and Carisolv group (nonsignificant difference)

P2: Comparison between polymer bur group and conventional group (significant difference)

P3: Comparison between Carisolv group and conventional group (significant difference)

Data expressed as median (minimum-maximum); $p$, probability; *, significance $<0.05$

Table 5: The mean values of the total viable bacterial count before caries removal and after caries removal among the three groups

\begin{tabular}{llllll}
\hline & & Polymer bur group & Carisolv group & Conventional group & $p$ value \\
\hline Before & Mean & 18,315 & 19,725 & 19,148 & 0.78 \\
& \pm SD & 6105 & 6575 & 6383 & $<0.001^{*}$ \\
After & Mean & 909.0 & 476.0 & 357.0 & 119.0 \\
& \pm SD & 303.0 & 158.7 & $\mathrm{P} 2=<0.001^{*}, \mathrm{P} 3=0.17$ \\
\hline
\end{tabular}

Data expressed as mean \pm SD

SD, standard deviation; P, Probability; *, significance $<0.05$

Test used: One-way ANOVA followed by post hoc Tukey

P1: Significance between polymer bur and Carisolv groups (significant difference)

P2: Significance between polymer bur and conventional groups (significant difference)

P3: Significance between Carisolv and conventional groups (non-significant difference)

of these two minimally invasive techniques in comparison to traditional mechanical techniques clinically and microbiologically.

Caries detector dye was used to assess the clinical efficacy of caries removal as it was more accurate and overcome the drawbacks of visual and tactile methods according to findings reported by Kuboki et al. ${ }^{10}$ in 1983 . The visual and tactile methods of caries detection were subjective and variable amongst practitioners.

In the present research results, regarding the median of caries detector dye scores, the conventional group median was significantly lower than the polymer bur group median, which means that the conventional method is more efficient clinically in caries removal. This is in agreement with Prabhakar and Kiran ${ }^{11}$ in 2009 who found that carbon steel round burs remove carious lesions more efficiently than polymer burs but they tend to contribute to the over-preparation of the cavity.

Also, the median of caries detector dye scores of the conventional group was significantly lower than the Carisolv group median, which means that the conventional method is more efficient clinically in caries removal. This is in agreement with Pandit et al. ${ }^{12}$ in 2007 and Kochhar et al. ${ }^{13}$ in 2011 who found that the efficacy of caries removal was higher with Airotor than Carisolv.
No significant difference was observed between the polymer bur group and the Carisolv group medians, regarding the caries detector dye scores. This is in accordance with the results reported by Soni et al. ${ }^{14}$ in 2015 who found no significant difference between polymer bur and Carisolv for efficacy of caries removal clinically.

The efficacy of caries removal was the highest with the conventional method because it tends to over-prepare the cavities due to lack of tactile sensation. This resulted in gross rapid removal of tissue with reduced control over the whole process. Thus, it was not always apparent to the operator when the true clinical endpoint was reached. Consequently, the excavation procedure continued in healthier dentin leading to eventual over preparation. ${ }^{3}$ Thus, this made the cavities prepared by the mechanical method appear less stained or not stained by the caries detector dye due to over preparation. ${ }^{15}$

Tactile and visual judgments and caries detector dyes can be used to evaluate whether or not infected dentin was removed. Unfortunately, none of them is a completely reliable guide to distinguish caries infected and caries affected dentin. Caries detector dyes can stain areas of sound dentin, including those adjacent to the dentino-enamel junction, besides the dentinal structure demineralized by bacterial metabolites. ${ }^{16,17}$ Rates of 
bacterial detection in caries were inversely proportional to the lightness of the carious dentin stained with a caries detector dye. When dentin is stained light pink, it should not be removed to prevent excessive tissue removal. ${ }^{18}$

The present study results demonstrated that the mean working time for caries removal was significantly longer in the Carisolv group compared with that in the conventional group. This is in agreement with the results reported by Pandit et al. ${ }^{12}$ in 2015 who found that Carisolv took a significantly longer time for caries removal compared to the conventional method.

Also, the mean working time for caries removal was significantly longer in the Carisolv group compared to that in the polymer bur group. This is in agreement with the study conducted by Divya et al. ${ }^{19}$ in 2015 who reported similar results.

The increased operating time taken by Carisolv gel can be attributed to its repeated applications. An average of 3-4 applications were done for the cavity preparation in our study. Multiple times of inspection (visual examination and tactile sensation) added to this. The cavity was rinsed for inspection, as the cloudy gel made the examination difficult. All of these factors increased the operating time of the Carisolv.

On the other hand, regarding mean caries removal time, no significant difference was observed between polymer bur and conventional groups, which is in accordance with the results reported by Medioni et $\mathrm{al}^{20}$ in 2016 who found that the mean time for caries removal did not significantly differ between the polymer bur and the conventional method.

After completion of the treatment, patient satisfaction toward the treatment was evaluated using the facial image scale. The results of the present study revealed that the median of the facial image scale scores was significantly lower in the polymer bur group compared with that in the conventional group. This means that the children in the polymer bur group were more satisfied than those in the mechanical group, which is in agreement with Allen et al. $^{9}$ in 2005.

Also, the median of the facial image scale scores was significantly lower in the Carisolv group compared with that in the conventional group. This indicates more patients' satisfaction in the Carisolv group than those in the conventional group. This is in agreement with Chowdhry et al. ${ }^{21}$ in 2015 who concluded that Carisolv was more accepted by the children than the conventional mechanical method.

On the other hand, no significant difference was observed between the median of the facial image scale score of the polymer bur group and the Carisolv group.

Patient satisfaction was higher in the polymer bur and Carisolv groups than that in the mechanical group. This may be attributed to the painless removal of dental caries without local anesthesia.

Also, administration of local anesthesia in the conventional group is painful and has tingling and numbness sensation which is unpleasant to many patients. In addition to unpleasant sound and vibrations of the high- and low-speed hand-pieces. All of these may have contributed to less patient satisfaction.

The microbiological results of this study revealed that the mean values of total viable bacterial count after caries removal were significantly higher in the polymer bur group compared with that in the Carisolv group. This means that Carisolv was more effective microbiologically in bacterial count reduction than the polymer bur. This is in agreement with the results of Divya et al. ${ }^{19}$ in 2015 who found that Carisolv was more effective microbiologically in caries removal than the polymer bur.

Also, the results of our study revealed that the mean values of viable bacterial count after caries removal were significantly higher in the polymer bur group compared with that in the conventional group. This means that the conventional mechanical method was more effective microbiologically in caries removal than the polymer bur. This is in agreement with the results of Hassan et al. ${ }^{22}$ in 2016 who found that the conventional method was more effective microbiologically in caries removal than the polymer bur.

On the other hand, no significant difference was observed between the mean values of viable bacterial count after caries removal between the Carisolv group and the conventional group. This is in agreement with the results of Azrak et al. ${ }^{23}$ in 2004 and Subramaniam et al. ${ }^{24}$ in 2008 who found that the antimicrobial efficacy of both methods was comparable and did not differ significantly.

The antimicrobial efficacy of Carisolv has been attributed to its content of sodium hypochlorite which is effective against bacteria in dental infections and cariogenic bacteria. ${ }^{25}$ While, the antimicrobial efficacy of the conventional mechanical method has been attributed to it is over the preparation of the dentin with its bacterial content.

\section{Conclusion}

The clinical efficacy of caries removal was highest with the mechanical method. Carisolv took the longest time for caries removal. Patient satisfaction was higher with Carisolv and polymer bur than the mechanical method. The antimicrobial efficacy of Carisolv and the mechanical method was higher than the polymer bur.

\section{Clinical Significance}

Carisolv is a viable alternative to the mechanical method in the management of dental caries, especially in children. Further studies are needed to assess the efficacy of caries removal by Smartburs $\|^{\oplus}$.

\section{References}

1. Hamama HH, Yiu CK, Burrow MF. Caries management: a journey between black's principals and minimally invasive concepts. Int J Oral Sci 2015;2(8):120-125. DOI: 10.19070/2377-8075-1500026.

2. Avinash A, Grover S, Koul M, et al. Comparison of mechanical and chemomechanical methods of caries removal in deciduous and permanent teeth: a SEM study. J Indian Soc Pedod Prev Dent 2012;30(2):115. DOI: 10.4103/0970-4388.99982.

3. Banerjee A, Watson T, Kidd E. Conservative dentistry: dentine caries excavation: a review of current clinical techniques. Br Dent J 2000;188(9):476. DOI: 10.1038/sj.bdj.4800515.

4. Banerjee A, Watson T, Kidd E. Dentine caries: take it or leave it? Dent Update 2000;27(6):272-276. DOI: 10.12968/denu.2000.27.6.272.

5. Hamama H, Yiu C, Burrow M. Current update of chemomechanical caries removal methods. Aust Dent J 2014;59(4):446-456. DOI: 10.1111/ adj.12214.

6. Murdoch-Kinch CA, McLean ME. Minimally invasive dentistry. J Am Dent Assoc 2003;134(1):87-95. DOI: 10.14219/jada.archive.2003.0021.

7. Munshi AK, Hegde AM, Shetty PK. Clinical evaluation of Carisolv in the chemico-mechanical removal of carious dentin. J Clin Pediatr Dent 2001;26(1):49-54. DOI: 10.17796/jcpd.26.1.Ir48727276478461.

8. Ericson D, Zimmerman M, Raber H, et al. Clinical evaluation of efficacy and safety of a new method for chemo-mechanical removal 
of caries. A multi-centre study. Caries Res 1999;33(3):171-177. DOI: 10.1159/000016513.

9. Allen $\mathrm{KL}$, Salgado $\mathrm{TL}$, Janal MN, et al. Removing carious dentin using a polymer instrument without anesthesia versus a carbide bur with anesthesia. J Am Dent Assoc 2005;136(5):643-651. DOI: 10.14219/jada. archive.2005.0237.

10. Kuboki Y, Liu C-F, Fusayama T. Mechanism of differential staining in carious dentin. J Dent Res 1983;62(6):713-714. DOI: 10.1177/00220345830620060401.

11. Prabhakar A, Kiran N. Clinical evaluation of polyamide polymer burs for selective carious dentin removal. J Contemp Dent Pract 2009;10(4):26-34. DOI: 10.5005/jcdp-10-4-26.

12. Pandit I, Srivastava N, Gugnani N, et al. Various methods of caries removal in children: a comparative clinical study. J Indian Soc Pedod Prev Dent 2007;25(2):93. DOI: 10.4103/0970-4388.33456.

13. Kochhar GK, Srivastava N, Pandit I, et al. An evaluation of different caries removal techniques in primary teeth: a comparitive clinical study. J Clin Pediatr Dent 2011;36(1):5-10. DOI: 10.17796/jcpd.36.1.u $242114 j 68847215$

14. Soni H, Sharma A, Sood P. A comparative clinical study of various methods of caries removal in children. Eur Arch Paediatr Dent 2015;16(1):19-26. DOI: 10.1007/s40368-014-0140-1.

15. Tonami K-I, Araki K, Mataki S, et al. Effects of chloramines and sodium hypochlorite on carious dentin. J Med Dent Sci 2003;50(2):139-146. DOI: 10.11480/jmds.500201.

16. Anderson MH, Loesche WJ, Charbeneau GT. Bacteriologic study of a basic fuchsin caries-disclosing dye. J Prosthet Dent 1985;54(1):51-55. DOI: 10.1016/s0022-3913(85)80069-x.

17. Yip $\mathrm{H}$, Stevenson A, Beeley J. The specificity of caries detector dyes in cavity preparation. Br Dent J 1994;176(11):417. DOI: 10.1038/ sj.bdj.4808470.
18. Iwami $Y$, Shimizu A, Narimatsu $M$, et al. The relationship between the color of carious dentin stained with a caries detector dye and bacterial infection. Oper Dent 2005;30(1):83-89.

19. Divya G, Prasad MG, Vasa AAK, et al. Evaluation of the efficacy of caries removal using polymer bur, stainless steel bur, Carisolv, papacariean in vitro comparative study. J Clin Diagn Res 2015;9(7):ZC42. DOI: $10.7860 / \mathrm{jcdr} / 2015 / 12705.6202$.

20. Medioni E, Rocca J-P, Fornaini C, et al. Histological evaluation of three techniques for caries removal. J Oral Sci 2016;58(4):583-589. DOI: 10.2334/josnusd.16-0225.

21. Chowdhry S, Saha S, Samadi F, et al. Recent vs conventional methods of caries removal: a comparative in vivo study in pediatric patients. Int J Clin Pediatr Dent 2015;8(1):6. DOI: 10.5005/jp-journals-100051275.

22. Hassan AF, Yadav G, Tripathi AM, et al. A comparative evaluation of the efficacy of different caries excavation techniques in reducing the cariogenic flora: an in vivo study. Int J Clin Pediatr Dent 2016;9(3):214. DOI: $10.5005 /$ jp-journals-10005-1366.

23. Azrak B, Callaway A, Grundheber A, et al. Comparison of the efficacy of chemomechanical caries removal (Carisolv ${ }^{\mathrm{TM}}$ ) with that of conventional excavation in reducing the cariogenic flora. Int J Pediatr Dent 2004;14(3):182-191. DOI: 10.1111/j.1365-263x.2004.00535.x.

24. Subramaniam P, Girish Babu K, Neeraja G. Comparison of the antimicrobial efficacy of chemomechanical caries removal (Carisolv ${ }^{\mathrm{TM}}$ ) with that of conventional drilling in reducing cariogenic flora. J Clin Pediatr Dent 2008;32(3):215-219. DOI: 10.17796/jcpd.32.3.1r08w6k1 478865 u7.

25. Ercan $\mathrm{E}$, Özekinci $\mathrm{T}$, Atakul $\mathrm{F}$, et al. Antibacterial activity of $2 \%$ chlorhexidine gluconate and $5.25 \%$ sodium hypochlorite in infected root canal: in vivo study. J Endod 2004;30(2):84-87. DOI: 10.1097/00004770-200402000-00005. 